\title{
THE CURRENT SITUATION OF SUPPORTED EMPLOYMENT IN SPAIN: ANALYSIS AND PERSPECTIVES BASED ON THE PERCEPTION OF PROFESSIONALS ${ }^{1}$
}

Word count: 6877 words (article + abstract)

\section{Introduction}

Supported employment emerged in the United States during the 1980s (Wehman, 1981; Wehman, 1992a; Wehman, 1992b). From there it spread to Canada and progressively to those countries in the Western world where integration policies are well established. Bellver (2001) and Saloviita (2000) contributed data on the implementation of supported employment in Europe during the 1990s. Pallisera (1996) also collected data from pioneer programmes on supported employment introduced in a number of European countries in the early 1990s. Despite the diversity of contexts and terminology employed in each case, it is a fact that all these projects share identical goals and similar methodologies. Supported work programmes provide people with disabilities with the necessary support, both within the workplace and outside it, for them to be able to carry out their work in an ordinary environment of the community. The professionals that run the programme provide the support needed by both the worker with disabilities and the host employment environment (employment agents and fellow workers). They intervene in the employment environment

\footnotetext{
${ }^{1}$ PALLISERA, M.; VILÀ, M.; VALLS,P. (2003).“The Current Situation of Supported Employment in Spain: analysis and perspectives based on the perception of professionals". Disability \& Society, Vol. 18, No 6 796-
} 
by analysing the tasks that can be carried out by the worker and by developing the traininglearning processes so that workers with disabilities can learn to do their job correctly and independently. Each placement must be of a highly individualized nature, in accordance with the characteristics of each worker with disabilities, each job to be performed and each employer company. It must be recognized that these programmes are more effective than the traditional sheltered structures, taking into account the number of placements achieved in the mainstream employment market.

In European countries, supported employment co-exists with "traditional" sheltered employment programmes and services, which offer employment to people with disabilities in special environments. The implementation process of supported employment and its final consolidation depends on the links set up with the sheltered sector, the state social welfare policy and other factors. According to previous studies carried out in the same context as ours (Pallisera et al, 2001 and 2002a), the theoretical benefits of supported employment would include a greater general level of satisfaction in the worker, increase in self-esteem, personal changes that lead to improvements in their relationships with friends and family, economic gains that allow them to improve their prospects in other areas of their lives, and improvements in their social/personal skills related to carrying out their work (responsibility, initiative, accepting authority, etc.). Having said that, it is at present difficult to implant a social services model that could completely replace sheltered work for the strategies of supported employment. It must be remembered that a detailed analysis of each person with disabilities would be required in order to determine exactly the working 
environment and the intensity of support required, all of which needs to be done within the bounds of the economic and labour structure of each geographical area.

This paper seeks to analyse the evolution of supported employment programmes in Spain, most of which have been carried out during a major period of expansion of the sheltered sector that began during the 1990s. At present, supported employment is emerging as more efficient than the sheltered sector in achieving placements for workers in the mainstream employment market. Despite this fact, legal developments arising from recent social welfare policies do not encourage the consolidation of supported employment. The first section of this paper briefly traces the evolution of employment integration of people with disabilities in Spain up to the present co-existence of both the sheltered and supported employment sectors. Following this, we present the results of research involving professional workers in supported employment programmes, with their observations and evaluations of the current situation. Without doubt, what the workers themselves think of the work they do is a fundamental aspect and worthy of study. The present paper only reflects the view of the professionals, because of the great complexity and range of the subject. This data enables us to consider proposals to extend the experience of supported employment and thereby improve the employment situation of people with disabilities in our society. 


\section{Employment integration for people with disabilities in Spain: sheltered employment versus mainstream employment with support schemes}

\subsection{The 1980s: the return to democracy and the first regulations concerning services for adults with disabilities; regulation of sheltered employment}

The Franco dictatorship (1939-1975) gave way to a transition period during which the Spanish democratic institutions were reinstated, but it was not until 1982 that the Spanish parliament passed the Law on the Social Integration of Persons with Disabilities (LISMI). The LISMI set up social and employment integration services for people with disabilities in a spirit of achieving educational, cultural, social and employment advancement of people with disabilities by means of integration into institutions of a general nature, except when the circumstances of the disability require specific attention in special services and centres (Art. 6).

Section VIII of the LISMI deals with the subject of employment integration for people with disabilities. The main goal of this policy was to integrate people with disabilities into the mainstream employment system or, failing that, incorporate them into the production system by means of sheltered employment (Art. 37). When full integration was not possible, alternative services were envisaged. The Spanish law provided for two different models of sheltered workplaces for adults with disabilities: the Special Employment Centre (SEC) and the Occupational Centre (OC). The goal of the SECs was to provide an environment that would facilitate productive employment for people with disabilities in 
exchange for remuneration and personal and social adjustment services for the worker (Art. 42). The Occupational Centres provided a non-productive alternative with assistance for adults with disabilities who were considered unable to work in a SEC.

The SECs were designed with the dual goal (Art. 42) of "ensuring remunerated employment and providing services (...) while at the same time creating a model for the integration of as many unemployed people as possible into mainstream employment”. The structure and organization of a SEC are similar to those of an ordinary company, but include other aspects of a more social nature. According to Esteban (1999:201), the SEC regulations are characterized by two outstanding features. Firstly, all or nearly all of the workers must be disabled. Secondly, the government may subsidize up to $50 \%$ of the guaranteed minimum wage and up to $100 \%$ of the employer's contribution to the workers' insurance. Employers can also receive a grant of up to €12,048 for every stable placement created.

It is worth mentioning the quota system here as one of the measures taken to facilitate the placement of people with disabilities in mainstream employment. The quota system was brought in with Article 38.1 of the amended LISMI, which obliged employers of 50 or more workers to reserve $2 \%$ of positions in the company for people with disabilities. Spain thus conformed to the typically European quota policy, a measure that dates back to the First World War. Thornton $\left(2000^{\mathrm{a}}\right)$ states that two thirds of the member countries of the European Union are currently using some form of quota system, notwithstanding the questionable effectiveness of this type of measure. According to Esteban (1999:14), 
positive value should be placed on the reserve system as a means of guaranteeing the integration of workers with disabilities into the mainstream employment market. In Spain, however, there has been reiterated failure to observe this law, compounded by the lack of any form of inspection or sanctions for offenders.

\subsection{The 1990s: the slow emergence of supported employment as an alternative means of fostering integration of people with disabilities into the mainstream employment market}

In the Spanish context, the first projects to be implemented under the supported employment system occurred in the early 1990s, and from the mid-nineties onwards this type of initiative has become increasingly frequent. Catalonia is currently one of the autonomous communities of Spain with most projects currently operating along these lines.

Verdugo et al (1998) analysed the progressive introduction of supported employment in Spain and also made a quantitative study of existing programmes and the beneficiaries of their services. Up-to-date data on the characteristics and impact of supported employment programmes can be found in Verdugo and Jordán (2001) and Pallisera et al (2002b and 2002c). The first of these studies consists of a descriptive analysis of the situation concerning supported employment in Spain. The data was obtained through a questionnaire designed to supply information on the users, professionals, financing, economic resources and costs involved in supported work programmes. We wanted to gauge the stability of these programmes in comparison with sheltered work services. This study presents results from the data recovered from 43 services that provided supported employment in December 1999. The last two of the above references refer to research carried out recently in Spain, 
and contain an approximate description of the implementation of supported employment programmes: users, training given, job forecasts, work placement monitoring, public awareness-raising and the professionals. The information was obtained by means of a questionnaire which was sent out during 2001 to various services. Forty questionnaires were returned.

These studies show the considerable increase in services, especially during the second half of the 1990s. More specifically, Verdugo and Jordan (2001) point out that there were 24 programmes in Spain in 1995, 35 in 1996 and a total of 43 in 1999. Pallisera et al (2002b and 200c) report that 7,000 placements into mainstream employment were achieved under these programmes during the 1995-2000 period. However, the authors also point out that the lack of legal framework for these services has given rise to a wide variety of different models of funding and organization, and different frequency, length and extent of placement monitoring. This gives rise to an unstable and precarious situation for the professional workers involved in the programmes and for the programmes themselves.

\subsection{The first years of the new century: sheltered employment versus mainstream employment, the current situation}

At the beginning of the new century the situation is as follows. First, the sheltered employment model that was regulated in the 1980s is now widespread practice. This same tendency can be observed in most Western countries (Visier, 2000), although in Spain the increase has been spectacular, with numbers almost doubling over a ten-year period. Mora (2000:434) points out that there were 21,284 persons working in SECs in 1998 whereas ten 
years previously, in 1988, there were 5,018 persons working in this type of centre, which indicates an average placement increase rate of around 30\% per annum. However, we must bear in mind that comparison between SEC figures and supported employment placements is currently misleading in the Spanish context, as Bellver pointed out (Verdugo and Jordan, 2001:8). This is due to the fact that the two systems have dissimilar legal situations and different degrees of reliable funding. However, the increase in the number of placements in sheltered centres has worked against the attainment of one of the goals of these services, namely that of facilitating access to the mainstream market. According to Visier (2000:37), the low transition rates go some way towards explaining the increased demand for placements within the sheltered system and the growth of the sector, but also reflect concern for the evolution of the situation of the workers with disabilities in these centres.

Secondly, parallel to the growth of the sheltered employment sector, supported employment has also undergone considerable development. However, this system still requires proper legal recognition and reliable funding mechanisms in order to function correctly. Supported employment is currently developing as a result of a number of different professional initiatives, but these programmes have not yet been included in the social welfare service network for people with disabilities.

There has been no government guarantee of coordination between the services that operate within the sheltered employment framework (SECs) and the supported employment programmes. The schemes envisaged by the 1997 MTAS-CERMI agreement (between the Spanish Ministry of Labour and Social Affairs and the Spanish Committee of Disabled 
People’s Representatives) and the Comprehensive Plan for Disabled Persons, 1997-2002, introduced innovative guidelines to encourage the transition from sheltered companies to positions in mainstream employment, and to promote supported employment and other programmes. In practice, the Spanish Committee of Disabled People's Representatives (CERMI) did not bring enough pressure to bear for these guidelines to be developed in any operative manner. For this reason, any currently existing coordination and information pools are the result of the good will and availability of professionals working in the field. Despite the lack of official regulation, the professionals involved in these services are striving to achieve the official SEC goal of fostering the placement of people with disabilities in mainstream environments.

At the beginning of the year 2000 a new regulation was brought into force: Royal Decree 27/2000, which established exceptional alternative measures to compliance with the reserve quota for workers with disabilities. It allows public and private companies to be partially or totally exempt from having to contract people with disabilities provided they contract services from protected centres or else provide donations or sponsorship of a financial nature to services working to promote the placement of people with disabilities. This regulation falls into the category of "offset contribution systems” and differs from the quota system in that it allows companies to make a financial or compensatory contribution to a special fund aimed at generating the corresponding proportion of jobs for people with disabilities.

In the context of an increase in supported employment programmes and the progressive 
organization of professional lobbies demanding regulation of the service and reliable funding, these "alternative measures" came as a bitter disappointment to the sector. They were regarded as a step backwards on the path towards complete integration of people with disabilities into work and society.

\section{The evolution of supported employment in Spain: analysis by professional workers of the factors that encourage this form of employment integration}

After this overview of the employment integration situation in Spain, we will now proceed to a more detailed study of the links between sheltered employment and mainstream employment, in order to find out the factors that may determine the consolidation of supported employment in the Spanish context. We are especially concerned with the observations and analyses of the professional workers involved in the progressive advance of supported employment initiatives during the 1990s. We will look at their evaluation of the current regulations, suggestions for change and new proposals based on their shared experiences over the years. We must not forget the importance of the views of the workers and the information they can provide. They are the real protagonists of the paradigmatic changes in the integration of people with disabilities into the various environments in which they live. Much as they important, it is not the objective of this paper to gather the views of people with disabilities themselves.

Case studies were carried out in the Autonomous Community of Catalonia in order to 
collect and contrast these assessments. A semi-structured interview designed for the purpose was conducted with professionals working in 19 centres and services in Catalonia (thus covering $90 \%$ of known services). We interviewed the persons in charge of the services and/or other persons directly involved in employment placement processes. The interviews were carried out between October 2001 and February 2002. Among these services we found a wide variety of operational modes and target groups for training and placement schemes, but all the services shared a common use of support schemes for the placement of workers with disabilities.

The interviews were transcribed in full between February and April 2002. On completion of this part of the process, the data was sifted to extract the most significant statements, observations and tendencies by the professional workers involved in this field, which will now be discussed in order to gain a more detailed insight into the professionals’ positions on the issues raised in the course of the interviews.

The data is presented in two steps. We have taken as our starting point the observations and evaluation by the professionals on the uneasy relationship between the sheltered employment services and the supported employment programmes. We then go on to consider their observations on current regulations, focusing on the reserve quota in ordinary companies, the "alternative measures” to hiring workers with disabilities, the economic and tax advantages benefiting companies that accept placement and the regulation of supported employment programmes. 


\subsection{The starting point: the uneasy relationship between sheltered employment services and supported employment programmes}

The evolution of employment integration of people with disabilities in Spain has raised the issue of the complex relationship existing between the sheltered employment sector and the supported employment programmes. The huge growth of sheltered employment has not been followed by the transition of these workers into the mainstream employment market. It stands to reason that one of the main criticisms levelled at these services is to question the practical application of their integration policies.

In this context, supported employment provides a method that facilitates this transition. However, the lack of regulation for supported employment programmes hinders coordination with sheltered employment services. Although both services are striving towards the same theoretical goals, in practice, joint enterprise is rarely undertaken between the two sectors working in the field. Thus, professional workers in supported employment services mention that attempts to channel some persons with disabilities into SECs were rejected on the grounds of insufficient productivity. This situation is truly paradoxical, when we remember that the SECs' goal is precisely to hire low performance workers who cannot be easily integrated into mainstream employment, and in return for this service they receive large subsidies and tax relief for each placement achieved.

“There are SECs that give a very distorting image... many young people who could very well earn their living on the ordinary market end up there with the excuse that the SECs guarantee them more job security. And then, when this SEC asks you for workers, or when you go along and say: "Hey, look! I have these 8 or 9 young people who can't aspire to anything better than a job in a SEC", they tell you "Yeah, OK. We'll put them on the waiting list." But those people never get anywhere, because all the other ones who are better able to work get in first even though they are younger. By law, the SECs have to 
make money, so they take the ablest workers and in the end you just don't know what to say to the disabled ones.” (Centre 13).

"We have some people who are very hard to place in mainstream companies, so we try to pass them on to a SEC, but sometimes, to our surprise, the SEC doesn't want them either, because of their low work performance. (...) There are some cases that we pass on because we think that they just can't go straight into an ordinary company. There are other cases though that we pass on because we know that the person needs to earn a wage and accepts the situation on the understanding that we will keep them informed as to other offers of employment. The SECs don't always get the point and they get annoyed with us and they say: "That one is ours now! Leave him here with us now and don't be making him other offers! Just as I had him trained!” Well now, this can lead us into some pretty tense situations, because the workers are caught in the crossfire, and then they say "Look, if you get any offers for me, don't let them know about it. Don't ring me here, ring me at home.” And that's just pathetic...” (Centre 6)

The binomial "mainstream employment" versus "sheltered employment" has been criticized in different ways, depending on where these criticisms come from. Observers in the sheltered employment sector often raise the issue that people with disabilities who leave SECs to seek employment in the ordinary market return to the SEC after a short period due to the lack of understanding given to them in mainstream surroundings. Let us take a look at what the person in charge of a supported employment service has to say on this subject.

"Talking to a social worker from a SEC that was about to close down, I asked him if they wanted us to channel any of their workers into mainstream employment and he said "Whenever they try it they end up coming back..." I hear that being said all over the place but I personally don't know of any cases... If I ask "Can you tell me about one of them, tell me about one case, give me the name of somebody who that happened to, who went to work in a company and then wanted to go back because they didn't like it?" then they reply "Yeah, well, that's what I've heard."

"Yes, I've heard that too, been hearing it for years, but I don't know of any cases myself!" (...) I can give you data on SEC workers who are asking for better pay or for normal employment conditions. There's this sort of general, preconceived idea that they are better off there, and in the end they get to believe it themselves." (Centre 3).

The fact of the matter is that the SECs are perceived by the workers and especially by their families as safer and more stable employment environments than those on the mainstream 
market.

"Their environment is safer, the parents feel more at ease, the young people feel better, more protected, and it suits lots of them, that's for sure, it's obvious, isn't it? Here we have two of them who went to work in a private company one year, and another one another year, and they all said that they wanted to come back to the SEC.” (Centre 14).

"For some workers it is hard to leave the SEC for a private company, because very often in the SEC they are in their own atmosphere, they have their girlfriend there, everybody knows them and they are all the same. And when they go somewhere else, there are some who feel that they are a failure, but there are others that don't, of course, because there are lots of nice people working out there too.” (Centre 5).

A preconceived idea exists that SEC workers are protected from fluctuations on the employment market and are therefore in less danger of losing their jobs than workers in mainstream companies. However, our fieldwork highlighted the fact that some SECs have in fact closed down and dismissed their workers and other SECs dismiss their workers after a three-year temporary contract, just before they have to give them a permanent contract.

This also happens in many mainstream companies.

"In " $\mathrm{X}$ " special centres the policy is to give three-year contracts and sack the workers before having to make them permanent, and then they take on more people. This happens in laundries... and a whole lot of other companies... I know because then they come here to me. And the policy, well, I don't know if it still happens or if it just used to, is to throw them out after three years so as not to make them permanent. There aren't all that many permanent contracts in the SECs, maybe there are with the mentally disabled, but not with the other disabled people. But the mental people, after they've had money deducted for the canteen, their leisure activities and the association, they end up getting €60 cash in hand!” (Centre 10).

Apart from differences between the services in the strict employment sense, there are other factors involved that create shades of difference between supported employment and the SECs. The main difference is that the SECs are included in the service network for people with disabilities and can therefore channel their workers towards other services, such as 
accommodation, sport and leisure activities. Like the SECs, all these services are segregated but do provide an answer to the demands from families and workers alike for services beyond the employment context.

\subsection{Do the current regulations facilitate placement of people with disabilities in mainstream employment?}

Firstly, in response to questions on the quota system (the obligation of a certain category of company to hire a given number of workers with disabilities), reports from the different services agreed that the legal framework exists (i.e., the LISMI) but has not been sufficiently developed to facilitate placements. The problem will continue until the government takes measures to enforce the regulations. The legal obligation for certain companies to hire people with disabilities was substantially modified by the Spanish Parliament in 2000 with the "alternative measures" amendment to which we have already referred above. We believe that, at the time of writing, the obstacle to the placement of people with disabilities is not the failure to observe the law, but the fact that this (unobserved) law was modified in favour of the sheltered employment sector.

Secondly, the professionals in supported employment services are extremely reticent with regard to the "alternative measures" that enable certain types of company to avoid the obligation of hiring workers with disabilities by subcontracting out to SEC services.

"They (the alternative measures) are a disaster because, in the first place, there is no pressure put on businesses to comply with the law, which means that the only pressure that we have noticed is when there are subsidies involved. Since companies eligible for a subsidy from the Ministry of the Environment or Industry have to declare that they comply with the $2 \%$ quota, they sometimes ring us up and ask "Hey, what have I got to do to get the 
subsidy?” And then they race off and do it. But otherwise there's no sort of pressure put on them. If the company isn't asking for an official subsidy, nobody goes along to them and says "Listen, if you don't comply with the $2 \%$, you have to pay." So, they didn't use to comply with the $2 \%$ and now they don't comply with either the $2 \%$ or the alternative measures. But as well as that, there's another thing, the option they have of giving a donation to a foundation or to a SEC... This option has created a sort of rivalry between the different bodies in our sector, trying to get in there... This hasn't happened in our case, not because we're better than the rest, but because we're a federation and not a foundation or an official public service, so we couldn't get in there anyway... But you do see a good few people going straight to the companies offering to be receivers of donations... I think that is not very positive... They should set up a fund and then, with all the bodies in the sector working together, decide how to spend the money." (Centre 6).

Thirdly, we analysed the comments made on the economic benefits for mainstream businesses hiring people with disabilities. In certain conditions, these benefits are considered to encourage placements. However, there is a consensus of opinion that considers the economic incentives to be of limited interest and probably not attractive enough for the companies to take on these workers, especially in the case of people with psychical disabilities.

One centre in particular brought up the specific issue of the need to promote part-time contracts to benefit people with disabilities. At present, companies often reject the part-time option on the grounds that they require longer working hours and cannot face the additional cost of hiring two people for the same job. Part-time contracts bring in fewer economic benefits than permanent full-time contracts.

In order to encourage placements on the open employment market, another interviewee suggested that mainstream placements should receive the same subsidies as SEC placements. 
"The law should work in such a way that companies that take on disabled people get the same advantages as SECs. Several businessmen have said that to me. I was monitoring a publishing company and somebody said "I can't compete with you, with that SEC here in Barcelona that publishes books. They don't pay a penny to the Social Security but I have to pay...” There are people who say that the SECs are unfair competition. Well, whether it's unfair or whatever, it’s still competition.” (Centre 5).

The interviewees insist on the need to increase the economic benefits for businesses that hire people with disabilities, regardless of the contract mode chosen.

"In fact, it's the same old story. What the businessman wants is somebody to do the work. So here we go again...if you have a person who can do the work, but it takes them a bit longer, you can't tell the businessman that the contract is in his interest, because that's not true. It all depends on the type of contract. If it's a permanent contract or a one-year contract, it is in his interest, but if it's any other type of contract, there's no compensation.” (Centre 6).

Finally, we should discuss the comments and evaluations made regarding the need to regulate supported employment services. Most of the services have now been in operation for many years and, as well as monitoring current placements, are also having to provide extra support for previous placements where either temporary or continuous monitoring is needed due to changes in tasks or in the workplace. The lack of regulation and regular funding for these services make it hard to carry on and increase the workload of the professionals.

Mention was also made of the need for supported employment to be integrated and coordinated within the service network for adults with disabilities. Coordination is also needed between all the different bodies working towards the common goal of placing people with disabilities in employment. There are several obstacles to coordinating the two types of services at present. First of all, employment placement services are still largely 
unknown. Furthermore, the SEC is perceived by the families as a safer and more protective environment for the worker.

“... In theory, a SEC gives more, gives more stability, sure, everything is... they make everything much more... it is easier for the families... the families have to be really sure about going into mainstream employment, because otherwise, well... what happens is, people go back to the SEC.

-... As a parent, you have to be really sure. Parents start to have their doubts about it, and when they've been here for a year, or two, and it's an effort... in the end the only thing they see is that their kid stays at home every day, doesn't get up, has regressed again... and a lot of parents who used to say "No SECs!" are back there with a SEC, you bet they are..." (Centre 2).

\section{Conclusions: guidelines to encourage the consolidation of supported}

\section{employment in the Spanish context}

The above analysis highlights the fact that the government should make a greater effort to effectively promote and facilitate the contracting of people with disabilities for jobs in the mainstream environment. There has been no political determination to enforce the quota system, and the current compensatory contribution system on offer to companies not only discourages direct hiring of people with disabilities but also reinforces the sheltered employment sector. The compensatory system is reminiscent of practices more associated with charity organizations than with a true philosophy of social and employment integration and the development of the potential of persons with disabilities. The regulation undoubtedly constitutes a step backward on the road towards a fairer society for all. A new approach is needed to provide the means to actively help people with disabilities integrate into employment within their own community. 
The quota systems and the compensatory contribution systems are not the only ways of guaranteeing employment placements. Thornton (2000a) considers that nowadays these systems are no longer mutually exclusive and furthermore states that in order to be viable the systems must be backed up by other complementary measures. Economic incentives for contracting companies and support in the workplace are needed. These two instruments can be used to reinforce the integration policy, if required by the context. In the Spanish context, our analysis of the data collected shows that neither of these instruments has been applied in any particular way.

The economic incentives offered to contracting companies are regarded as scant, and only of significance in the case of permanent full-time contracts. Many people with disabilities find it hard to maintain a full-time employment schedule, and businesses receives hardly any economic compensation for part-time contracts. It is for this reason that the disabled employment services call for the need to extend the economic compensations to all the usual forms of work contract. The government gives more economic grants to the special employment centres (SECs) for each job created than to companies that decide to hire a person with disabilities. This is obviously one of the paradoxical situations to be found in the current regulations that hinder the placement of people with disabilities in mainstream environments.

We have already pointed out the virtual lack of political and economic encouragement for supported employment programmes. This is a general tendency found in many European countries. According to Bellver (2001), although supported employment is perfectly in line 
with the European Commission policies (2001) for the achievement of the maximum degree of social integration, in practice most governments still spend more on segregated services than on social integration. In Spain, the growth of supported employment has given rise to an incipient umbrella association of professionals working within this service calling for the regulation of supported employment, proper funding to guarantee the continuity and stability of the programmes, and the recognition of supported employment as another alternative for the integration of people with disabilities. The professionals' claims are backed by researchers working in the field of supported employment in Spain: Bellver (2001), Jordán (2001), Verdugo and Jordán (2001) and Pallisera et al (2001).

Recognition of supported employment is an essential prerequisite for the programmes to be included in the social welfare placement network thereby providing a coordination framework between the programmes and the sheltered employment services. Efforts must be made to coordinate projects that share the same theoretical goals but use dissimilar means to achieve different employment options for people with disabilities. Thornton (2000b) points out that coordination is up against many different political obstacles due to fragmentation of funding responsibility, conflicting political aims, multiplicity of service suppliers, and sometimes adherence to very different philosophies. There are likewise many different factors in Spain behind the difficulty of achieving coordination between the various services.

- The different approach of the "workshops", which were originally set up as specific services and are somewhat lacking as places of integration. With the diversification of 
- The over-protectiveness of the government, with measures that foster the concept of charity and perpetuate an image of the person with disabilities as dependent on social handouts, instead of encouraging society and employment agents to undertake greater responsibility for the improvement of living conditions for all.

- The low public profile of the mainstream placement services for persons with special needs. More effort should be made to bring these endeavours before the public eye. Existing associations and other newly created instruments should encourage professionals from these services to report on their experiences and activities by taking part in congresses, conferences and other encounters. These bodies should also participate in forums and other areas of citizen debate in order to reach out to a wider public by informing people of the nature of their professional experiences.

The University also has an important role to play, and research groups working on diversity-related issues should be encouraged to collect more information on the social and employment integration process of people with disabilities. Research projects should be carried out in collaboration with professionals involved in innovative schemes in this field. Only thus will it be possible to have a direct influence on the practical aspects of the schemes and to inform a wider public on the action being taken.

Finally, this study has reinforced our conviction that it is essential to involve people with 
disabilities themselves in the decisions that affect their lives, for instance through active participation in the management of the centres and services and through the involvement of the professionals in research concerning their work. We wish to stress here that the need for participation by people with disabilities includes all people with any type of disability. It is too often assumed that persons with psychical disabilities do not have sufficient resources to take decisions that affect their lives.

\section{ACKNOWLEDGEMENTS}

This research was partially funded by the Spanish Ministry of Science and Technology through BSO2000-321 project. Correspondence concerning this paper should be sent to Maria Pallisera; e-mail: maria.pallisera@udg.es

\section{REFERENCES}

BELLVER, F. (2001) Fifteen years of supported employment in Europe, Alimara. Revista de Treball Social, 48, pp. 65-73. (In Catalan)

EUROPEAN COMISSION (2001) EU Employment and Social Policy, 1999-2001: jobs, cohesion, productivity (Luxembourg, Office for Official Publications of the European Communities).

ESTEBAN, R. (1999) The Employment Contract and Disability (Madrid, IBIDEM). (In Spanish)

JORDÁN, F.B. \& VERDUGO, M.A. (2001) Supported employment in Spain, a consolidated fact, in: M.A. VERDUGO \& F.B. JORDÁN (Eds) Supports, Selfdetermination and Quality of Life, pp. 521-536 (Salamanca, Amarú). (In Spanish) 
Law 13/82 (7-4-82) on the Social Integration of Persons with Disabilities (LISMI). (In Spanish)

MINISTERIO DE TRABAJO Y ASUNTOS SOCIALES (1998) Employment and Disability (Madrid, IMSERSO). (In Spanish)

MORA, V. (2000) Spanish policies designed to encourage companies to employ and maintain in employment people with disabilities, in: L. VISIER, P. THORNTON \& V. MORA New International Perspectives on Employment of People with Disabilities, pp. 400-475 (Madrid, Escuela Libre Editorial). (In Spanish)

PALLISERA, M. (1996) Transition to Adult and Active Life of Persons with Disabilities (Barcelona, EUB). (In Spanish)

PALLISERA, M., BARRACHINA, S., FULLANA, J., LOBATO, J. \& VILÀ, M. (2001) Study of work integration of people with disabilities through supported employment in Girona, Suports, 5, 1, pp. 55-67. (In Spanish)

PALliserA, M., FULlANA, J., SOLER, P. \& VILÀ, M. (2002c) Study of Work Integration of People with Borderline Intelligence (Lleida, Diputació de Lleida). (In Spanish)

PALLISERA, M., FULLANA, J., JIMENEZ, P., RIUS, M., CARDONA, M., LOBATO, J. \& VILÀ, M. (2002b) The work integration process of people with disabilities in the ordinary market in Spain. Analysis of a questionnaire, in: D. FORTEZA \& M.R. ROSELLÓ (Eds) Education, Diversity and Quality of Life, pp. 769-778 (Palma de Mallorca, Universitat de les Illes Balears). (In Spanish)

PALliSERA, M., VILÀ, M., VALLS, P., RIUS, M., FULLANA, J., JIMÉNEZ, P., CARDONA, M. \& LOBATO, J. (2002c) The work integration of people with disabilities in 
the ordinary labour market in Spain. An approach through research, Siglo Cero (To appear) (In Spanish).

Royal Decree 27/2000 of 14th January 2000 establishing exceptional alternative measures to compliance with the reserve quota for disabled workers. (In Spanish)

SALOVIITA, T. (2000) Supported employment as a paradigm shift and a cause of legitimation crisis, Disability \& Society, 1, pp. 87-98.

THORNTON, P. (2000a) Employment quotas, levies and national rehabilitation funds for persons with disabilities: pointers for policy and practice, in: L.VISIER, P. THORNTON \& V. MORA, New International Perspectives on Employment of People with Disabilities, pp. 93-265 (Madrid, Escuela Libre Editorial). (In Spanish)

THORNTON, P. (2000b) International research project on job keeping and reinstatement strategies for people with disabilities, in: L. VISIER, P. THORNTON \& V. MORA, New International Perspectives on Employment of People with Disabilities, pp. 266-400 (Madrid, Escuela Libre Editorial). (In Spanish)

VERDUGO, M.A., JORDAN, F.B., BELLVER, F. \& MARTINEZ, S. (1998) Supported employment in Spain, Journal of Vocational Rehabilitation, 11, 223-232.

VERDUGO, M.A., JORDÁN DE URRIES, B. (2001) Overview of Supported Employment in Spain (Madrid, Ministerio de Trabajo y Asuntos Sociales - Real Patronato sobre Discapacidad). (In Spanish)

VISIER, L. (2000) Labour relations in sheltered employment, in: L. VISIER, P. THORNTON \& V. MORA, New International Perspectives on Employment of People with Disabilities, pp. 13-89 (Madrid, Escuela Libre Editorial). (In Spanish)

WEHMAN, P. (1981) Competitive Employment: New Horizons for Severely Disabled 
Individuals (Baltimore, Paul H. Brookes).

WEHMAN, P. (1992a) Achievement and Challenges: a Five-year Report on the Status of the National Supported Employment Initiative. 1986-1990. (Virginia Commonwealth University, Rehabilitation Research and Training Center on Supported Employment). WEHMAN, P. (1992b) Life beyond the Classroom. Transition Strategies for Young People with Disabilities (Baltimore, Paul H. Brookes).

\begin{abstract}
At present, supported employment is emerging in Spain. It must be recognised that these programs are more effective than the traditional sheltered structures, into account the number of placements achieved in the mainstream employment market. Despite this fact, recent legal developments arising from social welfare policies do not encourage the consolidation of supported employment. This paper briefly traces the evolution of employment integration of disabled people in Spain, and gives the results of research on professional workers in supported employment programs. This data enables us to consider proposals to extend the experience of supported employment and thereby improve the employment situation of people with disabilities in our society.
\end{abstract}

